\title{
Rancang Bangun Chatbot Untuk Meningkatkan Performa Bisnis
}

\author{
Eka Larasati Amalia ${ }^{1}$, Dimas Wahyu Wibowo ${ }^{2}$ \\ ${ }^{1}$ Politeknik Negeri Malang \\ ${ }^{2}$ Politeknik Negeri Malang \\ Email: 1'eka.larasati@polinema.ac.id, 2dimas.wahyu@polinema.ac.id
}

\begin{abstract}
ABSTRAK. Chatbot merupakan aplikasi / layanan yang berinteraksi dengan pengguna melalui percakapan teks. Chatbot bekerja untuk menggantikan peranan manusia dalam melayani pembicaraan melalui aplikasi pesan. Chatbot telah menjadi lebih populer di grup bisnis saat ini karena Bot memastikan semua pesan dari pelanggan bias ditangani dengan cepat dan perusahaan dapat menghemat biaya operasional. Selain itu dengan adanya chatbot tempat usaha bisnis dapat menyediakan layanan yang aktif selama 24 jam. Pada penelitian ini akan dibuat rancang bangun Chatbot menggunakan Chatfuel untuk mengembangkan usaha bisnis. Pada Bot yang dibangun ini dapat membantu pemilik bisnis untuk melakukan pencatatan pesanan, pemrosesan pesanan, pencatatan pelanggan, informasi lokasi bisnis dan memudahkan transaksi pembayaran.
\end{abstract}

Kata Kunci: Chatbot, Chatfuel, Bisnis

ABSTRACT. Chatbot is an application / service that interacts with custumers through text conversations. Chatbot works to replace the role of humans in serving talks through the messaging application. Chatbot has become more popular in today's business groups because Bot ensures that all messages from customers can be handled quickly and companies can save on operational costs. In addition, with the chatbot, business premises can provide active services for 24 hours. In this study Chatbot will be designed to use Chatfuel to develop a business. In this built bot can help business owners to record orders, process orders, record customers, business location information and facilitate payment transactions

Keywords: Chatbot, Chatfuel, a Business

\section{PENDAHULUAN}

Salah satu permasalahan yang dihadapi olehpara pelaku usaha saat ini adalah tidak imbangnya jumlah tenaga kerja dan permintaan pelanggan. Semakin hari jumlah pelanggan yang ingin memesan produk atau sekedar bertanya mengenai produk serta pelanggan yang ingin melakukan tracking order semakin banyak. Akan tetapi pegawai yang bertugas menangani hal tersebut tidak sebanding dengan permintaan yang masuk sehingga seringkali terdapat pelanggan yang diabaikan.

Chatbot berperan untuk membantu bisnis menangani ribuan pesan yang masuk lewat berbagai saluran komunikasi. Bot memastikan semua pesan dari pelanggan bisa ditangani dengan cepat. Teknologi chatbot banyak digunakan oleh para pelaku bisnis karena perusahaan dapat menghemat biaya operasional dan menyediakan layanan yang aktif selama $24 \mathrm{jam}$. Hal ini secara tidak langsung akan menjadi nilai tambah yang membuat konsumen lebih menyukai produk tersebut. Selain itu dapat menghemat jumlah tenaga kerja dan meningkatkan jumlah penjualan.

Chatbot merupakan aplikasi / layanan yang berinteraksi dengan pengguna melalui percakapan teks. Chatbot bekerja untuk menggantikan peranan manusia dalam melayani pembicaraan melalui aplikasi pesan. Ia menjawab kalimat demi kalimat yang dituliskan orang yang berada di ujung satunya. Chatbot memahami, belajar, dan berinteraksi layaknya manusia. Hal ini bisa terjadi karena adanya Artificial Intelligence atau kecerdasan buatan.

Platform framewok pembangun chatbot AI berbasis cloud semakin marak. Platform tersebut memungkinkan para developer untuk dapat membangun chatbot tanpa kode atau menggabungkan dengan bahasa pemrograman tertentu. Chatfuel sebagai framework pembangun chatbot atau bot builder telah digunakan oleh beberapa perusahaan tingkat dunia karena hanya memerlukan waktu respon yang singkat dalam menjawab banyak pengguna sekaligus.

Berdasarkan penjelasan di atas, diharapkan dengan adanya layanan Chatbot yang dibangun dengan Chatfuel sebagai bot builder dan Facebook Messenger sebagai platform channel chatting dapat memberikan solusi kepada para pelaku bisnis dalam penelitian ini adalah restoran untuk dapat mengembangkan usaha bisnisnya seperti belanja, layanan pelanggan, pesanan makanan, update berita, reservasi dan banyak lagi. 


\section{TINJAUAN PUSTAKA}

\section{A. Chatbot}

Chatbot adalah sebuah program komputer yang dirancang untuk menyimulasikan percakapan antar manusia. Chatbot dibekali dengan kecerdasan buatan dan pemrosesan bahasa alami yang membuat chatbot menjadi program komputer yang cerdas dan dapat menjawab pertanyaan yang diberikan oleh manusia. Proses chatbot dimulai dengan masukan dari pengguna menggunakan bahasa alami dan sistem akan menjawab dengan respon yang masuk akal atau bisa dikatakan cerdas untuk bahasa yang sebenarnya. Chatbots ini dapat digunakan dalam industri kecil atau bisnis untuk mengotomatisasi layanan pelanggan sebagai permintaan pengguna akan ditangani oleh chatbots sehingga mengurangi kebutuhan tenaga kerja dan pengeluaran manusia. (Rupesh Singh, 2018).

\section{B. Chatfuel}

Chatfuel adalah platform bot terkemuka untuk membuat chatbot AI pada Facebook. Dalam platform ini memiliki plugins, yang dapat menambah fungsi fitur pada chatbot yang akan dibangun. Platform tersebut memungkinkan para developer untuk dapat membangun chatbot. Seluruh data disimpan pada cloud. Agar chatbot dapat bekerja dibutuhkan Facebook Page. Satu Facebook Page hanya dapat digunakan untuk satu chatbot.

\section{IMPLEMENTASI SISTEM}

\section{A. Arsitektur Sistem}

Arsitektur sistem ditunjukkan pada Gambar 1. di bawah ini. Diawali dengan masukan teks dari pelanggan dalam hal ini pelanggan restoran yang menggunakan akunFacebook Page. Kemudian saat Chatfuel sebagai pembangun chatbot menerima masukkan teks dari pengguna, Chatfuel akan merespon jawaban chat sesuai yang telah admin tentukan sebelumnya. Chatfuel dapat memberikan jawaban dengan mencari kesesuaian block atau menjawab dengan teks berdasarkan masukan pengguna.

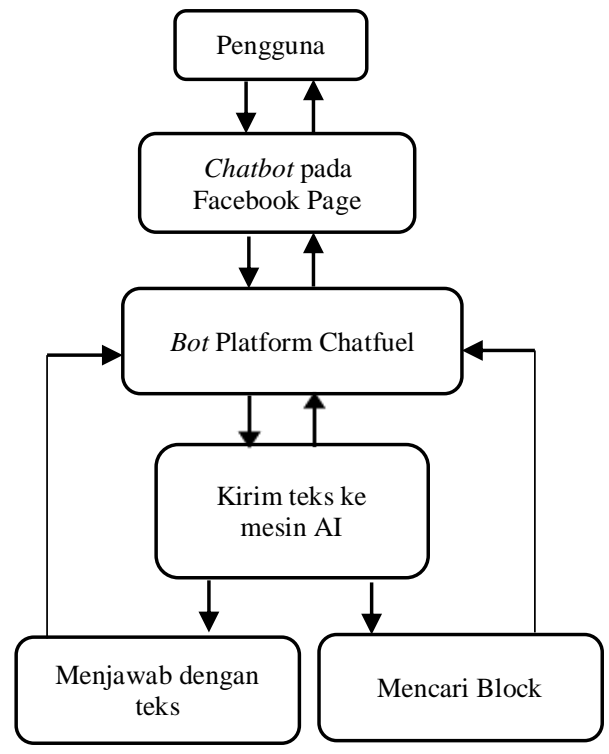

Gambar1. Arsitektur Sistem

Untuk mengimplementasikan Bot diperlukan langkah-langkah kerja, yaitu analisis sistem, desain, pengembangan, dan pengujian sistem.

1) Analisis Sistem

Pada tahap ini bertujuan untuk mengumpulkan informasi yang dibutuhkan dalam membangun sistem yaitu:

- Sub Basis Pengetahuan

Sub basis pengetahuan tentang informasi bidang usaha restoran.

- Sub sistem model

Sub sistem model dalam sisem ini berfungsi untuk mengimplementasikan sistem menggunakan metode Organizing Exercise Items, yaitu (a) nama bot; (b) group block; (c) set up AI; dan (e) section; 
- $\quad$ Sub sistem end pelanggan interface (UI)

Sub sistem UI berfungsi untuk menghubungkan antara pengguna dengan chatbot.

2) Desain

Chatbo tini dirancang untuk mempermudah interaksi dengan konsumen. Karena semua pertanyaan konsumen tentang produk, akan dijawab dengan cepat. Sistem ini akan dapat melakukan mengetahui lokasi, pencatatan pesanan, pemrosesan pesanan, pencatatan pelanggan update berita dan informasi lainnya. Selain itu dapat melakukan transaksi lebih mudah. Pembayaran dapat dilakukan dengan menggunakan kartu kredit.

\section{3) Pengembangan}

Untuk membangun chatbotl angkah-langkah yang perlu dilakukan adalah:

- Buat halaman Facebook Page untuk usaha bisnis yang dimiliki

- Membuat bot di Chatfuel

- Mengatur bot

- Mengatur AI

- Membangun block dan mengatur card

- Melatih frasa dan respons.

Tentukan frasa pelatihan untuk mencocokkan ucapan pengguna. Tentukan respons yang akan ditampilkan kepada pengguna yang dapat berupa frasa, gambar, suara, dan video.

Contoh frasa pelatihan ditunjukkan pada Gambar. 2.

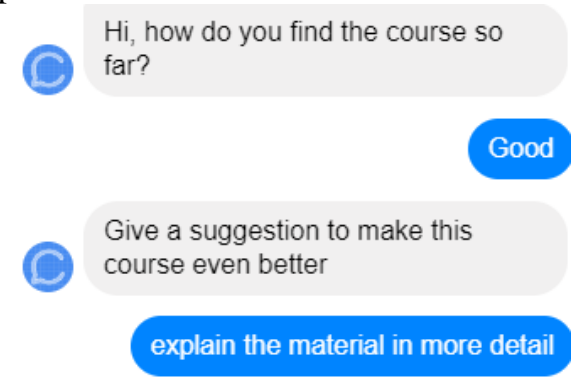

Gambar2. Contoh frasa pelatihan

\section{4) Pengujian}

Langkah terakhir dari proses implementasi adalah pengujian. Ada 2 langkah pengujian, yaitu selama pengujian pelatihan dan pengujian sistem. Selama pelatihan, pengujian adalah untuk menguji frase percakapan ke sistem dan memeriksa jawabannya. Jika respons tidak benar, frasa pelatihan tambahan diperlukan. Proses ini dapat dilakukan dalam alat pengembangan chatbot. Setelah menyelesaikan pengembangan sistem, pengujian sistem dilakukan. Hasil pengujian frasa percakapan ditunjukkan pada bagian 5 .

\section{B. Platform yang digunakan}

Platform yang digunakan untuk membangun chatbot dalam penelitian ini adalah Chatfuel. Keuntungan Chatfuel ini adalah dapat membangun chatbot yang didukung dengan kecerdasan buatan dengan mudah tanpa menggunakan bahasa pemrograman. Selain itu Chatfuel ini dapat diintegrasikan pada Facebook. Chatfuel ini didukung banyak fitur dan plugin, diantaranya adalah:

- $\quad$ Set Up AI

Digunakan jika pengguna ingin memberikan kecerdasan buatan pada bot yang dibangun.

- Broadcast

Berfungsi untuk mengirimkan pesan kepada pengguna.

- Configure

Berfungsi untuk menyambungkan bot dengan akun Facebook Page.

- Analyze

Berfungsi untuk menunjukkan statistic chatbot yang dapat membantu dalam mengembangkan chatbot yang dimiliki.

- Plugin Pelanggan Input

Berfungsi untuk mengajukan pertanyaan untuk pengguna bot dan menyimpan respon mereka keatribut pengguna.

- Plugin List 
Berfungsi menampilkan hasil produk, layanan bisnis, berita atau artikel.

- Plugin Share Location

Berfungsi untuk berbagi lokasi.

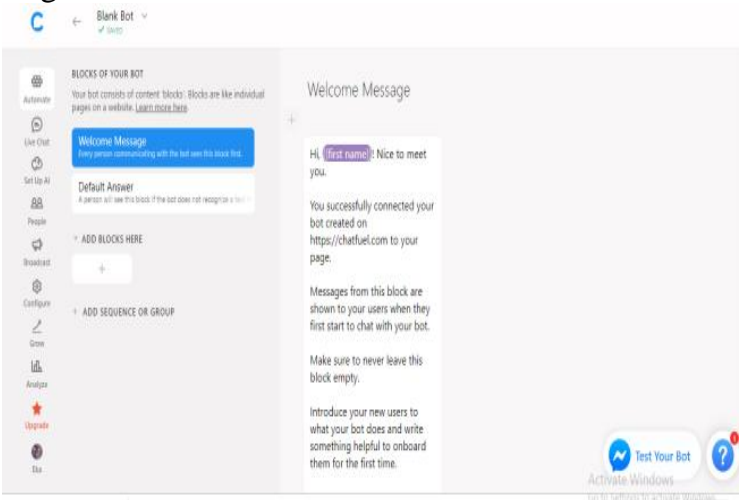

Gambar 3. Tampilan antarmuka Chatfuel

\section{HASIL DAN PEMBAHASAN}

Chatfuel adalah platform bot untuk membuat chatbot AI yang terintegrasi pada Facebook. Mendesain fitur chatbot perlu dilakukan saat awal akan membangun chatbot. Pada awal pembuatan Chatfuel akan ditampilkan beberapa pilihan template bot. Kemudian Chatfuel diintegrasikan dengan Facebook Messenger yang ada pada Facebook Page. Jika telah terintegrasi pengaturan AI dapat dilakukan pada fitur Set Up AI, Group dan penambahan rule. Chatfuel mempunyai beberapa fitur block yang mendukung logika program IFTHEN.

Frasa percakapan antara pengguna dan bot dilakukan dengan menambah kata kunci dan botreplies yaitu respon. Respon bot dapat berupa teks atau block yang sudah dibuat sebelumnya. Proses penentuan respon tidak hanya berupa teks tetapi dapat juga berupa suara, gambar, dan video.

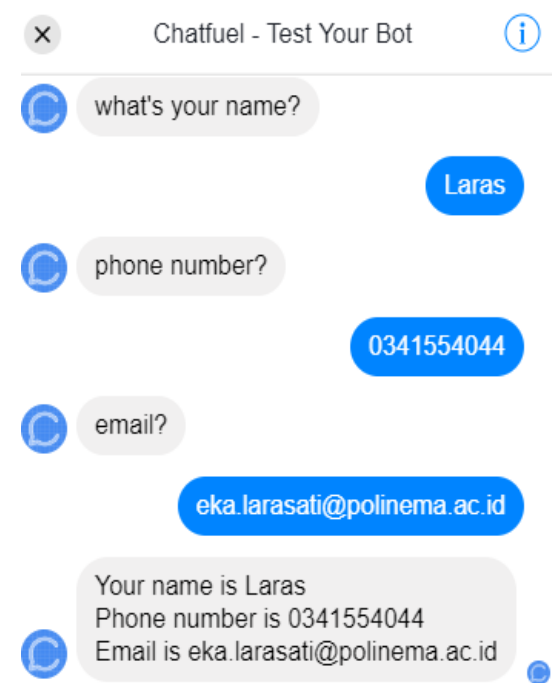

Gambar 4. Contoh frasa percakapan

Tampak pada Gambar 4 menunjukkan masukkan kata kunci yang sesuai dan Gambar 5 menunjukkan masukkan kata kunci yang tidak sesuai. 
what's your name?

What you've entered does not look

like a phone number. Please try

again.

Gambar 5. Contoh frasa percakapan tidak sesuai kata kunci

\section{PENGUJIAN}

Pengujian sistem dilakukan dengan menggunakan metode black-box testing. Metode ini digunakan untuk melakukan pengujian yang berfokus pada keluaran yang dihasilkan dari proses masukan yang terjadi. Tabel di bawah ini merupakan contoh beberapa pengujian yang dilakukan.

- Pengujian halaman produk

Tabel 1. Pengujian menampilkan produk

\begin{tabular}{cclc}
\hline Skenario pengujian & Masukkan & $\begin{array}{l}\text { Keluaran yang } \\
\text { diharapkan }\end{array}$ & Keluaran hasil \\
\hline $\begin{array}{l}\text { Mengakses menu beverages } \\
\text { untuk melihat detail produk } \\
\text { (fungsionalitas) }\end{array}$ & Klik menu beverages & $\begin{array}{l}\text { Halaman detail } \\
\text { produk }\end{array}$ & $\begin{array}{l}\text { Halaman detail } \\
\text { produk (valid) }\end{array}$ \\
\hline
\end{tabular}

- Pengujian menampilkan lokasi restoran

Tabel 2. Pengujian menampilkan lokasi

\begin{tabular}{cclc}
\hline Skenario pengujian & Masukkan & $\begin{array}{l}\text { Keluaran yang } \\
\text { diharapkan }\end{array}$ & Keluaran hasil \\
\hline $\begin{array}{c}\text { Mengakses menu locations } \\
\text { untuk melihat lokasi restoran } \\
\text { (fungsionalitas) }\end{array}$ & Klik menu locations & $\begin{array}{l}\text { Halaman detail } \\
\text { lokasi berupa peta }\end{array}$ & $\begin{array}{c}\text { Halaman detail } \\
\text { lokasi berupa } \\
\text { peta (valid) }\end{array}$ \\
\end{tabular}

- Pengujian mengirim pesanan pelanggan ke restoran

Tabel 3. Pengujian mengirim pesanan pelanggan ke restoran

\begin{tabular}{|c|c|c|c|}
\hline Skenario pengujian & Masukkan & $\begin{array}{l}\text { Keluaran yang } \\
\text { diharapkan }\end{array}$ & Keluaran hasil \\
\hline $\begin{array}{c}\text { Mengakses menu take away } \\
\text { untuk membuat formulir } \\
\text { penerimaan pesanan } \\
\text { pelanggan (fungsionalitas) }\end{array}$ & $\begin{array}{c}\text { Klik menu take } \\
\text { away }\end{array}$ & $\begin{array}{l}\text { Halaman formulir } \\
\text { penerimaan } \\
\text { pesanan }\end{array}$ & $\begin{array}{c}\text { Halaman } \\
\text { formulir } \\
\text { penerimaan } \\
\text { pesanan (valid) }\end{array}$ \\
\hline
\end{tabular}

\section{KESIMPULAN}

Berdasarkan hasil penelitian yang dilakukan terhadap implementasi chatbot untuk meningkatkan usaha bisnis beserta pembahasannya yang telah dilakukan, maka dapat disimpulkan bahwa Chatbot yang dibuat telah mampu membantu menjawab pertanyaan konsumen dengancepat, mengetahui lokasi, pencatatan pesanan, pemrosesan pesanan, pencatatan pelanggan dan informasi lainnya. Selain itu dapat melakukan transaksi lebih mudah. Pembayaran dapat dilakukan dengan menggunakan kartu kredit.

\section{DAFTAR PUSTAKA}

Bhavika R. Ranoliya, Nidhi Raghuwanshi, and Sanjay Singh. Chatbot for University Related FAQs. IEEE, 2016, pp1525-1530.

E. Pratt, "A Primer Artificial Intelligence and Chatbots in Technical Communication - A Primer," pp. 2-9, 2017. 
Nudtaporn Rosruen and Taweesak Samanchuen. Chatbot Utilization for Medical Consultant System. The 2018 Technology Innovation Management and Engineering Science International Conference (TIMES-iCON2018).

S. Divya, V. Indumathi, S. Ishwarya, M. Priyasankari, and S. Kalpana Devi, "A Self-Diagnosis Medical Chatbot Using Artificial Intelligence,” J. Web Dev. Web Des., vol. 3, no. 1, pp. 1-7, 2018.

S. Rupesh, P. Manmath, S. Nirmala, P. Harskumar, M.Nitin. Chatbot using Tensor Flow for small Businesses, in Proceedings of the 2nd International Conference on Inventive Communication and Computational Technologies (ICICCT 2018) IEEE Xplore Compliant - Part Number: CFP18BACART; ISBN:978-1-5386-1974-2.

W. Mokhammad Hadi, Sarosa M, T.H erman. Rancang Bangun Chatbot Pembelajaran Java Pada Google Classroom Dan Facebook Messenger. Jurnal Teknologi Informasi dan Ilmu Komputer (JTIIK) Vol. 5, No. 3, Agustus 2018, hlm. 287-296. 